\title{
One Float-assisting, Bulletproof, Stab-resistant Composite Clothes and Its Preparation Method
}

\author{
Xiang-hui Meng ${ }^{1, a^{*}}$, Gang Lu ${ }^{2}$ and Qi Yang ${ }^{3}$ \\ ${ }^{1}$ Troop 91872, Beijing, China,102442 \\ ${ }^{2}$ Ordnance Equipment Department of Naval Equipment Department, Beijing, China, 100841 \\ ${ }^{3}$ Troop 63867, Baicheng, China, 137001 \\ amxh0823@163.com
}

\begin{abstract}
Keywords: Multifunctional, float-assisting, bulletproof, Stab-resistant.
Abstract: A modulated float-assisting, Bulletproof, stab resistant cloth is designed; the preparation method and corresponding product are brought forward. The cloth is composed of the coat, the standardized modules and components. The cloth has a neck protection body, the coat and crotch portion protecting body. The neck protection body is unified with shoulder protection body to protect the body. The front and back part of the coat are designed into double-interlayer. The float-assisting layer is placed in the inner interlayer. The Bulletproof layer and the stab-resistant layer are placed in the outer interlayer. The lower hem of the coat is connected with the slice-shaped crotch protecting body. Multichannel braids are used for carrying light equipment and additionally arranged on the front slice of the coat. The utilization result showed that the modularization float-assisted, Bulletproof and stab-resistant clothes are light and handy, practical, reasonable in design and convenient to use and effectively play a safety protection role for personnel engaged in security work and military personnel.
\end{abstract}

\section{Introduction}

To help dealing with many critical situations in the course of duty for security staff, such as protection from attacks from light bullet or stab dagger and so on, researchers invented a variety kinds of Bulletproof, stab-resistant cloth preparation techniques ${ }^{[1-4]}$. These inventions can provide better protection for the majority of security personnel and also play a very important role in public safety protection. In 2009, Yang first prepared unidirectional prep composite orthogonal material with polyethylene fiber, Kevlar and polyarylate, then composite the material with biaxial oriented polyester film and made one new kind of Bulletproof, stab-resistant material with 50 70 layers ${ }^{[5]}$. In 2011, Li invented a Bulletproof and stab-proof material with high-performance fabrics coated with bonded material, one Bulletproof and stab-resistant cloth is prepared with multi-layered compound material which is made up of tiny bead of hard matters, ceramics or glass for example ${ }^{[6]}$.

According to the analysis about preparation technology and development trend of varied kinds of multifunctional Bulletproof and stab-proof cloth, current products can meet the normal requirement for security staff, however, these products are not quite suitable for maritime operations, maritime security tasks executed by special security personnel and so on. As a result, in order to develop multifunctional life-saving protective garment which comprehensively takes advantages of domestic high-performance protective materials, float-assisting materials and domestic preparation technology with independent intellectual property rights considering the feature of domestic male figure and special safety protection requirement for varied missions such as naval escort, maritime police on duty, fishery enforcement, anti-smuggling and so on, so that the functions such as carriage of individual portable equipment, float-assisting and body protection can be synthesize in one protective cloth by referring to the basic design factors such as structures, materials, and other advantages of positive buoyancy Bulletproof equipment (Bulletproof vests) developed by United States, Russia, Britain and other countries. 


\section{Analyses and Determination of Performance Requirement}

Float-assisting Performance. The basic parameters of domestic male figure referred in the research is the average height of 1.73 meter, the average weight of $70 \mathrm{Kg}$, at the same time the weight of supplies and equipment for single soldier is normally less than $13 \mathrm{Kg}$ in view of all kinds of tasks. Given the buoyancy of single soldier and safety margin, the whole protective cloth should offer more than $18 \mathrm{Kg}$ of positive buoyancy to make sure the head of the soldier stay above the water.

Bulletproof Performance. Present mainstream is apt to combined utilization of soft Bulletproof layer and removable hard bulletproof boards so that these two kinds of materials can be better arranged in group and the performance of Bulletproof. The design for collar protection body, shoulder protection body, neck protection body, crotch portion protecting body, inner core of Bulletproof clothing should be in accordance with police standard GA141-2010II, III and US NIJ0101.04III, so that the clothing can effectively endure strike from bullets of 92 type pistols, 54 type pistols, 79 type light machine gun and Uzi 9mm light machine gun of USA.

The design of removable hard bulletproof boards is in accordance with GJB4300-2002VI of China and NIJ0101.04III, NIJ0101.04IV of the USA, as a result the boards can effectively resist $5.8 \mathrm{~mm}$ bullets of 95 type automatic rifle, $5.8 \mathrm{~mm}$ rifle bullets of 97 type rifle.

Stab-resistant Performance. The system should at least be able to resist attack with kinetic energy of $24 \mathrm{~J}$, in the light of normal requirement on stab-resistant performance. The results showed that the stab-resistant performance of the cloth is in consistent with Chinese police GA68-2008 standard and US police stab-resistant standards.

\section{Designs and Preparation of Components}

The System and Its Components. The protective cloth has three major components: the coat, modular portable accessories and Bulletproof removable boards. The coat is constituted of the cover, stab-resistant layer, soft Bulletproof layer and float-assisting layer, etc; the modular portable accessories are designed into several standardized modules to hold varied kinds of portable supplies and equipment; Bulletproof removable boards are designed into couples and distinguished as front part and back part which is loaded into corresponding bags on the coat, as shown in Fig. 1.
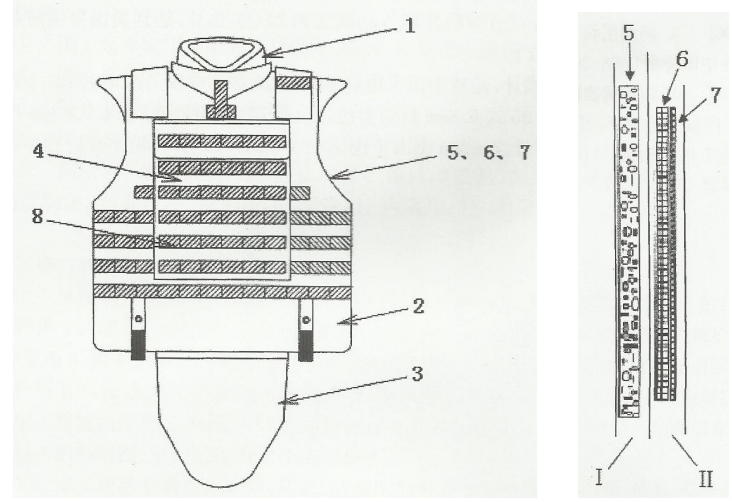

1. collar protection body, shoulder protection body, neck protection body; 2. Cover of coat; 3. Crotch portion protecting body; 4. Bags of Bulletproof removable boards; 5. Buoyancy layer; 6.Bulletproof layer; 7.

Stab-resistant layer; 8. Bulletproof removable boards.

Fig. 1 Structural Sketch map of the coat

Design of the Coat. The material of the coat is polyester fiber Oxford cloth which is waterproof, fire retardant and wear resistant. Considering the convenience command for dressing, requirement for flexible movement, diversified supplies and equipment, adaptability requirement for different waist and height, it's reasonable to design two sections as the front and back of the coat according to the design principles of ergonomic, each section has a double compartment layer to place the soft Bulletproof layer, stab-resistant layer and buoyancy layer in proper order. The inside lining cloth is black polyester mesh lining sandwich cloth which is beneficial to ventilation and cooling. Outside 
of each section of the coat, there are pockets with the size of $30 * 25 \mathrm{~cm}^{2}$ designed to hold removable Bulletproof boards and Multichannel braids suitable to load modular portable light equipment, for example flares, light sticks, communication tools, GPS locator, water bags, multi-purpose radio lequipment packages. Braids are also applied on the shoulder and waist outside the coat to fit people with varied height and waist. Crotch portion protecting body is connected to the front part of the coat with rough surfaced Velcro, which makes it easy to be disassembled.

Modular Design. The portable accessories, float-assisting layer, Bulletproof layer, stab-resistant layer, collar protection body, neck protection body, shoulder protection body, neck protection body and some other parts are designed into modules to form a complete set with the coat and the ribbon system, according to requirement on flexibility for combination of modules and facilitation to unload the cloth.

Integrative Collar-shoulder-neck protection Body. Collar protection body, shoulder protection body and neck protection body are integrated designed into unitary, the fabric of coat is polyester fiber Oxford cloth which is waterproof, fire retardant and wear resistant, and soft cotton is opted to protect joint of human body. The material of Bulletproof layer is double orthogonal super thin soft UD weftless cloth $\left(130 \sim 140 \mathrm{~g} / \mathrm{m}^{2}\right)$ made of ultra high molecular weight polyethylene fiber (UHMWPE). Surface density of the layer is $<6.8 \mathrm{~kg} / \mathrm{m}^{2}$, the protection area is $0.1 \sim 0.11 \mathrm{~m}^{2}$. All 2 shoulder protection bodies, 1 neck protection body, 2 collar protection bodies and 1 crotch protecting body are heat sealed with soft polyester waterproof cloth and then integrated with the coat. These design made the cloth comfortable and flexible for wearing, it can soundly meet the requirements for grade I Bulletproof performance and grade II stab-resistant performance according to GA141-2010.

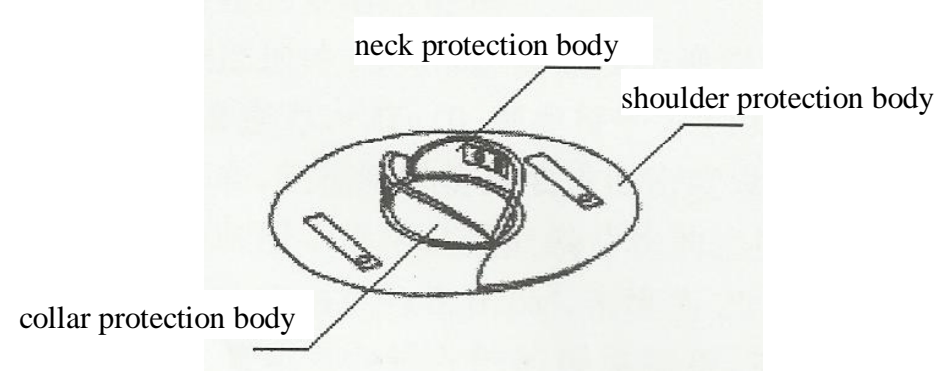

Fig. 2 The structure of integrative collar-shoulder-neck protection body

Based on ergonomics principle, modular design principle, combination design principle and analysis of investigation result, the design requirement is determined by inputting overall types of naval missions. Then the category, models, amounts, sizes and weights of more than 10 kinds of accessories are determined, standardized sizes for each module is determined. The position and fasten measures for each module is determined by analysis of human movement characteristics combined with facility requirement for accessing of accessories. The handcuffs box, for example, is designed to place handcuffs or rope. The size of the handcuffs box is $110 \mathrm{~mm}$ (length) * $50 \mathrm{~mm}$ (width) * 150mm (height), the whole module is mould pressed with hard PVC, a belt buckle tied the belt with the back of handcuffs box with the size of $50 * 70 \mathrm{~mm}$.

Float-assisting Layer. The standard weight of domestic male is set as $70 \mathrm{~kg}$, as a result the protective cloth should be able to provide positive buoyancy of more than $18 \mathrm{~kg}$ (fresh water). To meet the requirement for positive buoyancy, the domestic high density foam rubber materials (chemical name NBR-PVC, density $65 \mathrm{~kg} / \mathrm{m} 3$ ) is chosen as the material for float-assisting layer, and the material is a kind of safe non-toxic light float-assisting materials. The thickness of the layer is $20 \mathrm{~mm}$, the area of front layer $0.208 \mathrm{~m}^{2}$, the area of back layer $0.242 \mathrm{~m}^{2}$. Float-assisting material is sealed with taffeta PVC glue cloth to make sure the float-assisting layer is waterproof and convenient for disassembly and replacement.

Bulletproof Layer. The soft Bulletproof layer can meet requirements which are grade II for Bulletproof and grade I for fragment resistant of police standard GA141-2010. The layer is piled up 
with 40 high modulus polyethylene fibers woven cloth with intellectual property (UHMWPE), its density is $6.8 \mathrm{~kg} / \mathrm{m}^{2}$, which means that it's $10 \%$ lower than requirement of grade II standard GA141-2010, the requirements claimed in assignment book is meet. The overall area of the vest and crotch is larger than $0.28 \mathrm{~m}^{2}$, and the protective sleeve of Bulletproof layer is made of heat sealed black opaque nylon taffeta polyester waterproof cloth.

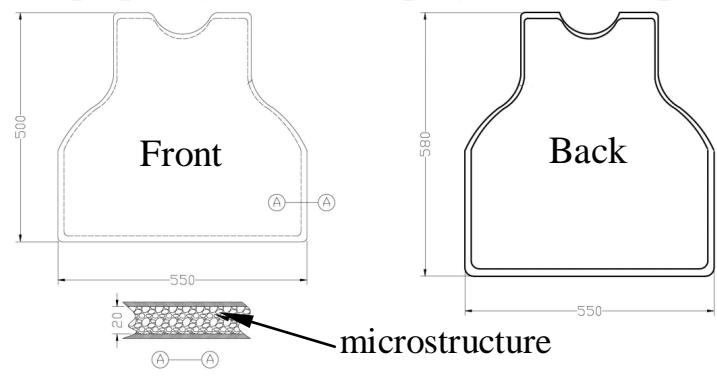

Fig.3 Sketch up for structure of float-assisting layer
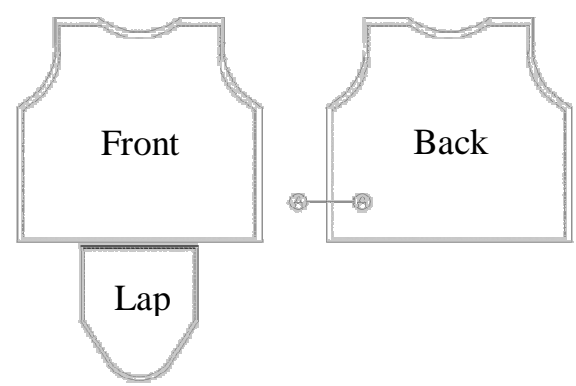

Fig.4 Sketch up for structure of bulletproof layer

Stab-resistant Layer. The material of stab-resistant layer is compounded with high performance lightweight aluminum alloy plate and high strength fiber canvas, which is of lower density and higher stab-resistant performance. The area of the stab-resistant is the same to the Bulletproof layer. The stab-resistant clothing is able to resist attack with kinetic energy of 24J. The results showed that the stab-resistant performance of the cloth is in consistent with Chinese police GA68-2008 standard and US police stab-resistant standards, the specified shape is shown in Fig. 4.

Removable Bulletproof Board. To improve the performance of Bulletproof and stab-resistant, removable Bulletproof boards are designed. Combined utilization of the boards and soft Bulletproof layer should meet demands required for Bulletproof performance indicated in grade VI GJB4300-2002. The radian of the boards is $\mathrm{R} 400$, and its density is $26 \mathrm{~kg} / \mathrm{m}^{2}$, size $300 * 250 \mathrm{~mm}$ (ceramic chip protection layer included), available protection area is $0.07 \mathrm{~m}^{2}$, which is in accordance with GJB5478-2006.

There are two kinds of material applied in the removable Bulletproof board: double orthogonal ultra high molecular polyethylene fiber UD weftless cloth is used to laminate the back plate, and the density of the plate is $13.3 \mathrm{~kg} / \mathrm{m}^{2}$; all 79 hexagonal lightweight silicon carbide ceramic plates are selected with thickness of $4.2 \mathrm{~mm}$ and side length of $30 \mathrm{~mm}$.

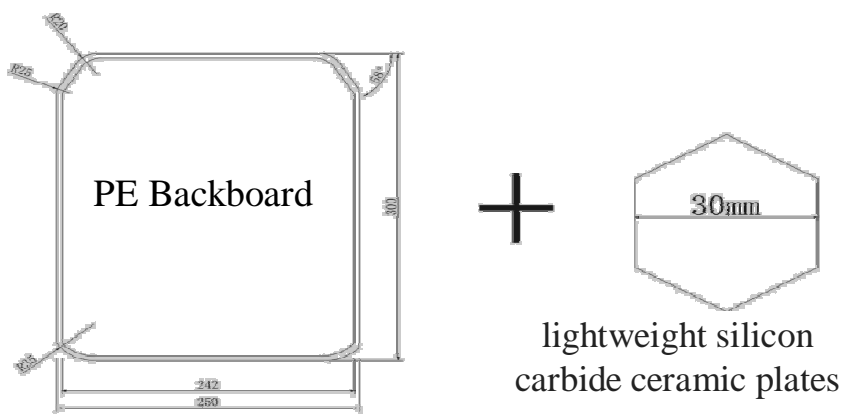

Fig.5 Sketch up for structure of removable bulletproof board

Portable Accessories. Based on ergonomics principle, modular design principle, combination design principle and analysis of investigation result, the design requirement is determined by inputting overall types of naval missions. Then the category, models, amounts, sizes and weights of more than 10 kinds of accessories are determined, standardized sizes for each module is determined. The position and fasten measures for each module is determined by analysis of human movement characteristics combined with facility requirement for accessing of accessories. The handcuffs box, for example, is designed to place handcuffs or rope. The size of the handcuffs box is $110 \mathrm{~mm}$ (length) * $50 \mathrm{~mm}$ (width) * $150 \mathrm{~mm}$ (height), the whole module is mould pressed with hard PVC, a belt buckle tied the belt with the back of handcuffs box with the size of $50 * 70(\mathrm{~mm})$. 


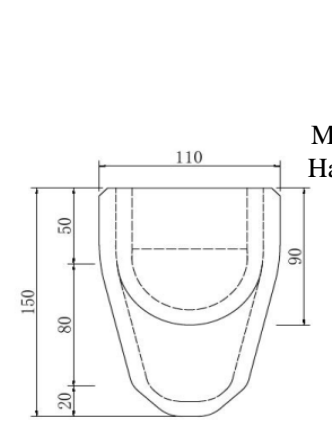

Face

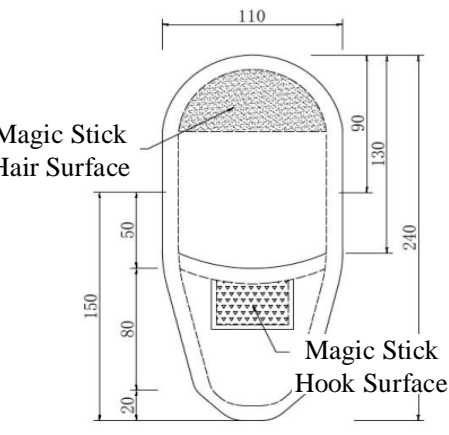

Flank

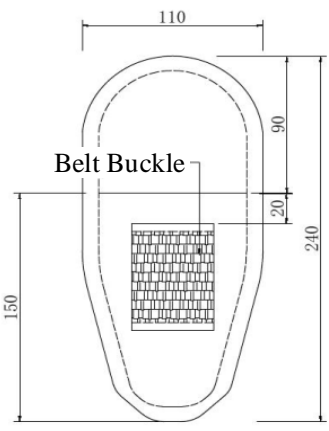

Back

Fig.6 The structure of handcuff box

\section{Method of operation}

Operation in Need of Float-assisting and Against Light Weapons. To resist from 92 type pistols which is in accordance with GJB4300-2002 Grade I, standard 54 type pistols which is in accordance with police standard GA141-2010 Grade II, 79 type light machine gun and Uzi 9mm light machine gun of USA, the cloth should be used as followed: (1) To put on neck protection body, shoulder protection body and neck protection body; (2) To load float-assisting layer in the inner interlayer of the coat, and Bulletproof layer in the outer interlayer; (3) To connect the crotch protecting body to the coat with rough surfaced Velcro.

Operation in Need of Close Fight. If close fight is necessary during the operation, the stab-resistant slices should be loaded outside of the Bulletproof.

Operation in need of resist weapon with great piercing power. To resist against automatic rifles or assault rifles, the stab-resistant layer should be replaced with one removable Bulletproof boards in the front and back of the coat.

\section{Conclusions}

As shown by the feedback from maritime security stuff and naval escort personnel by utilization in different missions, the protective cloth is designed reasonably, lightweight and practical. The cloth has great float-assisting property and relative larger protection area, it also integrated multiple protection functions such as Bulletproof and stab-resistant. The design of standardized module makes it more convenient to adjust the cloth for varied users and missions and carry more kinds of supplies and equipment etc. It's the special design that makes the best fully functional protection equipment in the world.

\section{References}

[1] Jiecai Zhou, Dengpeng Wu, Xiangzhi Yin, etc. Investigation of present situation and development of bulletproof and puncture-proof cloth [J]. Jiangsu Weave, issue 12, 40-43, 2011

[2] Xianchong Huang. Research of bulletproof and puncture-proof material and its development trend [J]. Weave Herald, issue 1, 87-91, 2013

[3] Yi Qu, Bin Wang, Qiaoli Qin, etc. Technology of bulletproof and puncture-proof cloth and its development trend [J]. Chinese Security \& Surveillance, issue 7, 55-59, 2013

[4] Xinling Fang, Hao Chang, Dongmei Xu, etc. Research on bulletproof and puncture-proof performance of Aramid UD fabric [J]. High-tech Fabric and the Appliance, issue, 3,45-48, 2015

[5] Nianci Yang, Zhiquan Wu, Mingqing Lin. One Bulletproof and stab-resistant material and its preparation methods, China, Patent, 101,881,582. (2009)

[6] Feng Li, Yinjian Li, Yingzhang Qu. One composite stab-resistant material and composite Bulletproof, stab-resistant material, China, Patent, 102,493,202. (2011) 